\title{
Estudo de Caso de Peça Moldada pelo Processo de Injeção-Compressão para Termoplásticos Utilizando Análise Computacional
}

\author{
Thyago M. Kiam, Nilson C. Pereira \\ Departamento de Engenharia de Materiais, Universidade Presbiteriana Mackenzie
}

\begin{abstract}
Resumo: O processamento de termoplásticos através do processo de injeção representa o principal método de fabricação de peças plásticas. Limitações do processo de injeção convencional, principalmente quanto à matéria-prima e configuração e funcionamento das máquinas disponíveis, tornam inviável a produção de produtos com grande área projetada e pequena espessura, como janelas automotivas e alguns tipos de lentes. Paralelamente, o processo de injeção evolui continuamente e há uma série de novas tecnologias geradas a partir do processo original, dentre elas o processo de injeção-compressão. No presente trabalho, utilizando análise computacional, estudou-se a produção de lentes de policarbonato através de dois processos distintos: injeção convencional e processo de injeção-compressão. A seqüência de estudos envolveu basicamente os seguintes pontos: estudo do padrão de preenchimento com conseqüente otimização do processo de injeção-compressão quanto à formação de linha de emenda; estudo da janela de processo para ambos os casos e comparação de alguns parâmetros principalmente tensão de cisalhamento e força de fechamento, por se tratarem de fatores limitantes na produção de peças com grande área projetada. Os resultados para o caso estudado comprovam grande vantagem na utilização do processo de injeção-compressão.
\end{abstract}

Palavras-chave: Injeção, injeção-compressão, simulação, CAE.

\section{Study of Injection-Compression Molded Part using CAE Analysis}

\begin{abstract}
The injection-molding of thermoplastics is the main process used in the production of plastics parts. There are some limitations in the conventional injection process, specially related to raw materials, machines configuration and operation, which hamper fabrication of thin parts with large areas such as car windows and lenses. On the other hand, the process has been improved continuously with several new technologies, going beyond the conventional injection molding process, including the "injection-compression" process. In this paper, using CAE (computer aided engineering) technology, the author studied the production of PC lens by both processes: conventional injection molding and injection-compression molding. The studies were basically conducted in the following sequence: flow pattern study and optimization of the injection-compression process focusing on the weld line size, molding window study for both cases and comparison of several parameters, particularly shear stress and clamp force - as they are key parameters for the production of large-area parts. The results confirm the advantages of the injection-compression process.
\end{abstract}

Keywords: Injection, injection-compression, simulation, CAE.

\section{Introdução}

Devido à filosofia de racionalizar e integrar diferentes funções em um mesmo componente surge a necessidade de se produzir peças com grande área e pequena espessura a partir de material termoplástico ${ }^{[1]}$. Nessa situação, podemos destacar a produção de peças óticas como lentes e janelas automotivas.

Em comparação com o vidro para esse tipo de aplicação, os polímeros oferecem vantagens como: menor densidade, menor preço e maior resistência ao impacto. Outra vantagem, inerente ao tipo de processo de conformação, é a possibilidade de se produzir um conjunto montado num único ciclo - como uma janela e seu suporte ou componente de fixação - através do processo de sobre-injeção. As principais desvantagens que podemos apontar comparando materiais plásticos ao vidro são: a menor resistência ao risco e à temperatura ${ }^{[2]}$.

Economicamente, a produção em larga escala de peças plásticas é mais atrativa - devido aos ciclos de produção em tempo diminuto e à possibilidade de se produzir diversas peças numa única etapa. Em contrapartida, não é possível obter esse tipo de peça (i.e. grande área e pequena espessura) através do processo de injeção convencional. Para atender essa demanda, destaca-se o processo de "injeçãocompressão"[2]. 
A diferença entre o processo de injeção convencional e o processo de injeção-compressão ocorre na etapa de preenchimento da cavidade, sendo que no processo de injeçãocompressão essa etapa pode ser dividida em duas etapas distintas:

a) Fase de injeção do material: uma quantidade específica de material é injetada na cavidade. Durante essa etapa, a cavidade apresenta volume maior que o volume da peça, devido à disposição das placas do molde parcialmente abertas $(\Delta \mathrm{h})$ como mostrado na Figura 1a; e

b) Fase de compressão: durante essa etapa o material injetado é comprimido através do completo fechamento do molde, promovendo assim o escoamento e total preenchimento da cavidade (Figura 1b). A etapa de recalque pode não ser necessária em alguns casos ${ }^{[2]}$. Através desse processo, é possível produzir peças com menor orientação molecular - devido aos menores valores de tensão de cisalhamento envolvidos - gerando peças com menor tensão residual e, portanto, menor propensão ao empenamento e melhor precisão dimensional. Outra vantagem está relacionada à pressão de preenchimento envolvida no processo menor que a pressão presente no processo convencional devido à menor restrição ao fluxo na cavidade resultando em menor solicitação da máquina quanto à força de fechamento aplicada no molde ${ }^{[1]}$.

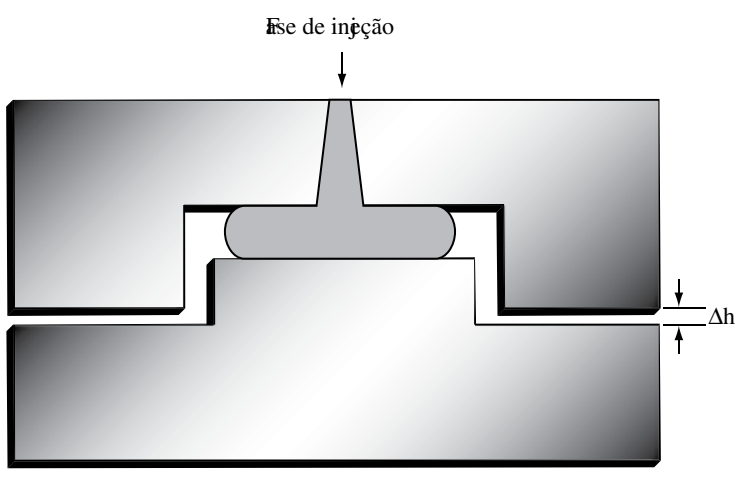

(a)

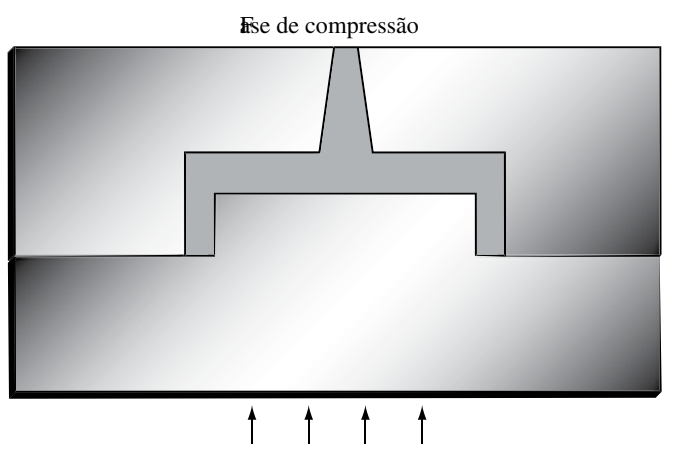

(b)

Figura 1. Processo de injeção-compressão.
Dessa forma, o processo de injeção-compressão possibilita a produção de peças com grande área projetada, boa qualidade ótica e dimensional ${ }^{[2]}$.

Num futuro próximo, os veículos automotivos serão equipados com janelas de grande área, produzidas com material termoplástico. O objetivo não será apenas proporcionar redução de peso. O uso de termoplásticos possibilitará maior liberdade de design se comparado ao vidro. 'Pontos cegos' - especialmente na parte traseira dos veículos automotivos serão reduzidos consideravelmente ou mesmo completamente eliminados, aumentando a segurança dos automóveis ${ }^{[3]}$.

\section{Materiais e Métodos}

\section{Ferramentas CAE}

As ferramentas CAE (computer aided engineering - engenharia auxiliada por computação) oferecem à equipe de projetos a possibilidade de realizar experimentos através de métodos computacionais. Esses experimentos, se realizados em condições 'reais', resultariam em grandes gastos associados a alterações no molde, manufatura e custo de operação e parada de máquinas. $\mathrm{O}$ grande potencial desse método é a possibilidade de testar novos "designs" e conceitos de molde através de método numérico: minimizando problemas antes do "nascimento" de um produto e possibilitando estudo do processo e qualidade da peça a custo relativamente baixo.

Consegue-se, portanto, grande flexibilidade na otimização do produto através de iterações virtuais - em detalhes como configuração das entradas de material no molde, detalhes no desenho da peça, condições de processo - e sua influência na manufatura e qualidade do produto final. Como resultado, é possível realizar experimentos que demandam dias ou mesmo horas, que de outra forma - tentativas e erros experimentais - despenderiam de semanas ou meses, resultando em grandes custos de modificações no molde ${ }^{[4]}$.

Para extrair todo potencial desse tipo de ferramenta, sua utilização deve ocorrer desde os primeiros estágios no processo de concepção de um produto. Na Figura 2, comparamse os custos associados a alterações no produto em diferentes estágios de um projeto. Através dos experimentos realizados

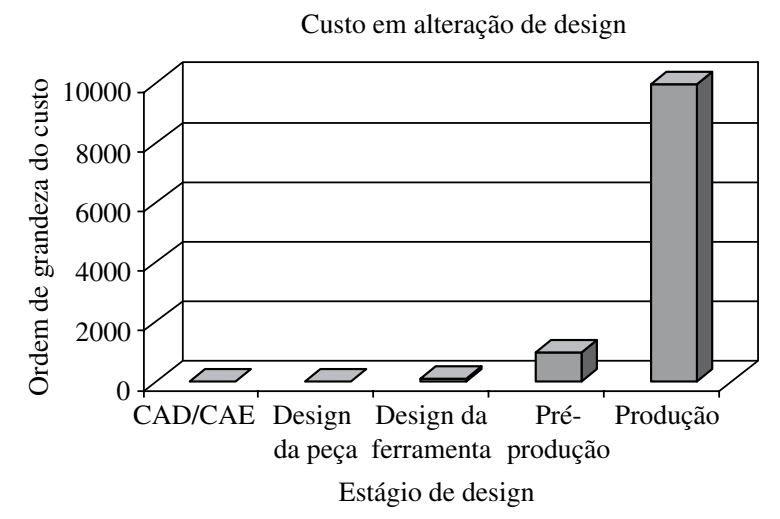

Figura 2. Custos envolvidos na alteração de um projeto. 
utilizando-se de "softwares" de simulação, minimiza-se futuras modificações corretivas, como posição das entradas, alteração de espessuras, devido a problemas como atrasos de produção, grande quantidade de refugos e dificuldade na regulagem da máquina injetora ${ }^{[4]}$.

No presente trabalho, foi utilizado o "software" Moldflow Plastics Insight 5.1.

\section{Experimental}

\section{Modelo e material}

A peça estudada consiste numa lente de $250 \mathrm{~mm}$ de diâmetro, com espessura variando de $6,0 \mathrm{~mm}$ na região periférica, até 2,0 mm na região central (Figura 3). Como condição de contorno para a entrada de material utilizou-se 7 nós na lateral da peça de forma a uniformizar o fluxo - representando uma entrada em leque.

Uma peculiaridade no processo de injeção dessa peça é a tendência do fluxo desenvolver velocidade diferenciada no centro e na região periférica da cavidade. Em seu centro, ocorre atraso no fluxo (hesitação) devido à restrição causada pela pequena espessura. Na região periférica da cavidade, o fluxo tende a acelerar, ou seja, efeito chamado de "racetracking". Como resultado, temos a formação de duas frentes de fluxo distintas que se encontram no final do preenchimento, formando linha de emenda (Figura 4).

As linhas de emenda ou solda são regiões que apresentam queda de propriedades mecânicas, principalmente se formadas a baixa temperatura. No caso de peças transparentes/ óticas, as linhas de emenda são indesejadas, devido à perda de qualidade estética.

Nas análises realizadas, utilizou-se modelo de elementos finitos representando o plano médio da peça. Na Tabela 1 são apresentados detalhes sobre o modelo de elementos finitos.

O material utilizado nos experimentos foi o policarbonato Lexan OQ4120R, produzido pela GE Plastics. Os principais detalhes da caracterização do material são descritos na Tabela 2.

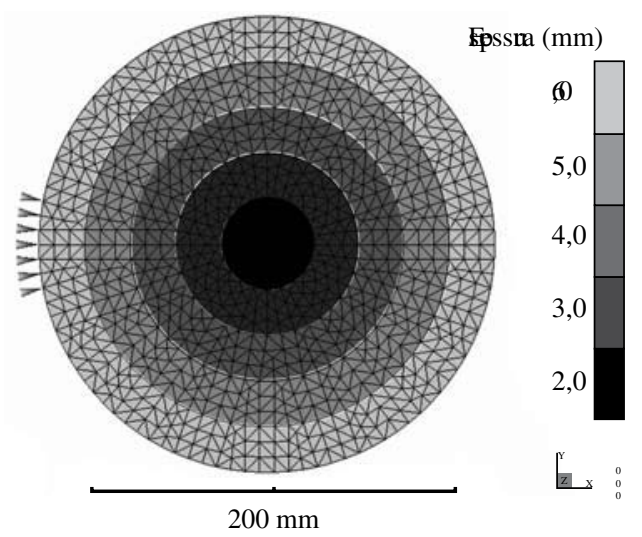

Figura 3. Modelo da lente.

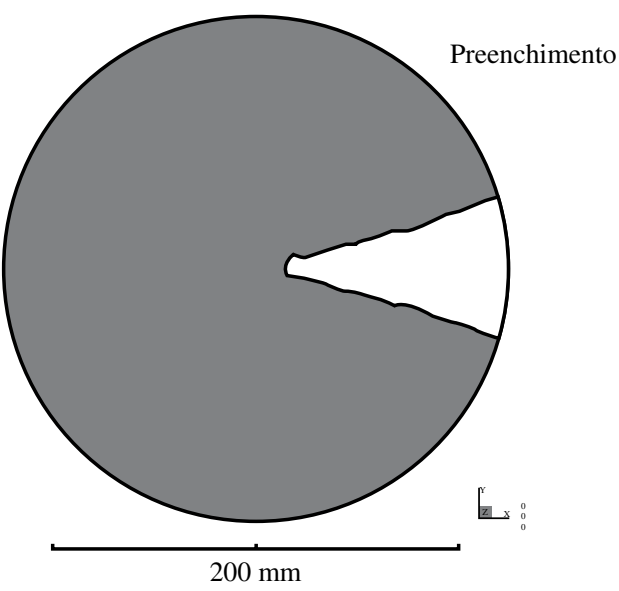

Figura 4. Formação de linha de emenda ou solda na peça injetada.

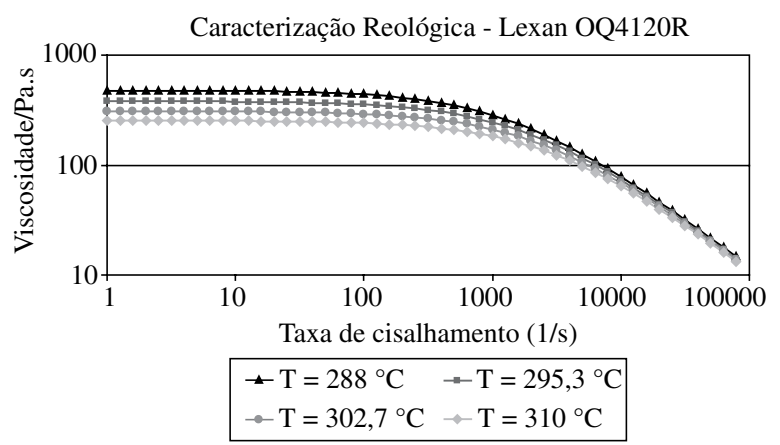

Figura 5. Caracterização reológica do material utilizado.

Tabela 1. Detalhes sobre o modelo.

\begin{tabular}{lc}
\hline \multicolumn{2}{c}{ Parâmetros } \\
\hline $\mathrm{n}^{\text {o }}$ total de elementos da peça & 1788 \\
$\mathrm{n}^{\text {o de nós }}$ & 944 \\
Volume da peça $\left(\mathrm{cm}^{3}\right)$ & 236 \\
Área projetada total $\left(\mathrm{cm}^{2}\right)$ & 491 \\
\hline
\end{tabular}

Tabela 2. Propriedades do material.

\begin{tabular}{|c|c|}
\hline Parâmetros & \\
\hline Nome do material & Lexan OQ 4120R \\
\hline 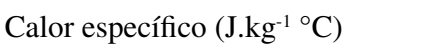 & 2079 \\
\hline Condutividade térmica $\left(\mathrm{W} . \mathrm{m}^{-1}{ }^{\circ} \mathrm{C}\right)$ & 0,26 \\
\hline Temperatura de transição $\left({ }^{\circ} \mathrm{C}\right)$ & 140 \\
\hline
\end{tabular}

A Figura 5 representa o gráfico da caracterização reológica do material: indicando a influência da temperatura e taxa de cisalhamento na viscosidade do material.

\section{Resultados e Discussão}

A primeira etapa na otimização do processo consistiu em realizar experimentos com o valor de abertura das placas, ' $\Delta \mathrm{h}$ ' como mostrado na Figura la e sua influência na qualidade da peça quanto ao tamanho da linha de emenda formada. Na Tabela 3 são descritos os principais parâmetros de processo adotados nos experimentos realizados na otimização da abertura de placa. 
Tabela 3. Parâmetros de processo - otimização do $\Delta \mathrm{h}$.

\begin{tabular}{lc}
\hline \multicolumn{2}{c}{ Parâmetros injeção-compressão } \\
\hline Temperatura do molde $\left({ }^{\circ} \mathrm{C}\right)$ & 85 \\
Temperatura do material $\left({ }^{\circ} \mathrm{C}\right)$ & 300 \\
Tempo de injeção $(\mathrm{s})$ & 2 \\
Comutação $(\%)$ & 98 \\
Abertura de placas $(\mathrm{mm})$ & variável \\
Atraso no fechamento $(\mathrm{s})$ & 2 \\
\hline
\end{tabular}

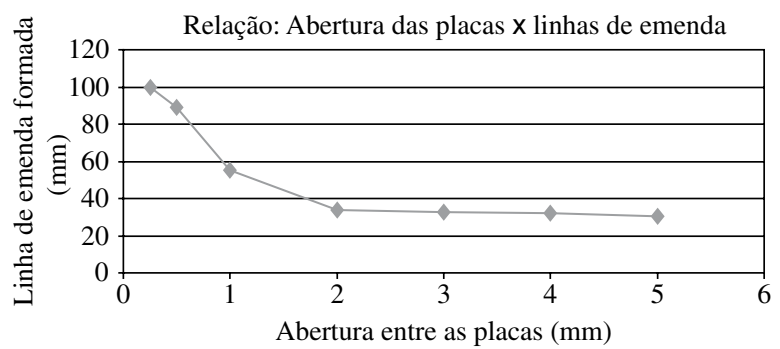

Figura 6. Variação do tamanho da linha de emenda em função da distância de abertura entre as placas.

No processo de injeção convencional, a linha de emenda formada possui cerca de $110 \mathrm{~mm}$. Nos estudos realizados, variou-se a abertura inicial das placas de 0,25 a $5 \mathrm{~mm}$. Os valores de comprimento da linha de emenda formada são apresentados na Figura 6. É possível, portanto, verificar que a partir de um valor de abertura nas placas de $2 \mathrm{~mm}$, a variação no comprimento da linha de emenda é mínima, ou seja, aproximadamente $30 \mathrm{~mm}$. Adotou-se, portanto, nas análises posteriores, abertura de $2 \mathrm{~mm}$.

\section{Determinação da janela de processo}

Durante a etapa preenchimento, ou seja, durante o escoamento do polímero fundido na cavidade, ocorrem dois fenômenos relacionados com a troca de calor:

1) Perda de calor do material fundido para as paredes da cavidade; e

2) Geração de calor devido ao cisalhamento do material fundido.

Uma vez que esses dois fenômenos influenciam a viscosidade do material e, portanto, a dificuldade em fazer escoar o polímero fundido. Há duas situações extremas:

- Alta velocidade de injeção (tempo de injeção curto): requer alta pressão para preencher a cavidade devido à alta energia e perda de carga envolvidas. Esse tipo de situação gera altos valores de taxa de cisalhamento; e

- Baixa velocidade de injeção (tempo de injeção longo): propicia grande troca de calor, resultando na queda de temperatura do material e conseqüente aumento na viscosidade durante o preenchimento, sendo necessária alta pressão para preencher a cavidade.

Essa relação gera um gráfico em forma de "U” (Figura 7). Existe uma região ótima em que os dois fenômenos (taxa de cisalhamento e troca de calor) se equilibram, requerendo o menor nível de pressão ${ }^{[5]}$.
Nos experimentos realizados para determinação da janela de processo, foram adotados os parâmetros de processo descritos na Tabela 4. Além disso, nos estudos realizados, variou-se o tempo de preenchimento de 1 a 6 segundos. Os valores de resposta de pressão são apresentados na Figura 8.

Devido à menor pressão necessária para preencher a cavidade, adotou-se 4 segundos como tempo de injeção nos próximos estudos.

Na Figura 9, são apresentados os valores de máxima queda de temperatura na frente de fluxo durante a fase de preenchimento da cavidade. A grande diferença de queda de temperatura entre os dois processos está principalmente relacionada ao grande atraso no fluxo para o processo de injeção convencional devido à variação de espessuras na cavidade. Para o tempo de injeção adotado de 4 segundos, o processo de injeção-compressão apresentou queda de temperatura 96\% menor que o processo de injeção convencional. Altas quedas de temperatura indicam alta propensão à ocorrência

Tabela 4. Parâmetros adotados na determinação da janela de processo.

\begin{tabular}{lcc}
\hline \multicolumn{1}{c}{ Parâmetros } & $\begin{array}{c}\text { Injeção } \\
\text { convencional }\end{array}$ & $\begin{array}{c}\text { Injeção- } \\
\text { compressão }\end{array}$ \\
\hline Temperatura do molde $\left({ }^{\circ} \mathrm{C}\right)$ & 85 & 85 \\
Temperatura do material $\left({ }^{\circ} \mathrm{C}\right)$ & 300 & 300 \\
Tempo de injeção $(\mathrm{s})$ & variável & variável \\
Comutação $(\%)$ & 99 & 99 \\
Abertura de placas $(\mathrm{mm})$ & não se aplica & 2 \\
Atraso no fechamento $(\mathrm{s})$ & não se aplica & variável \\
Velocidade de compressão $(\mathrm{cm} / \mathrm{s})$ & não se aplica & 1 \\
\hline
\end{tabular}

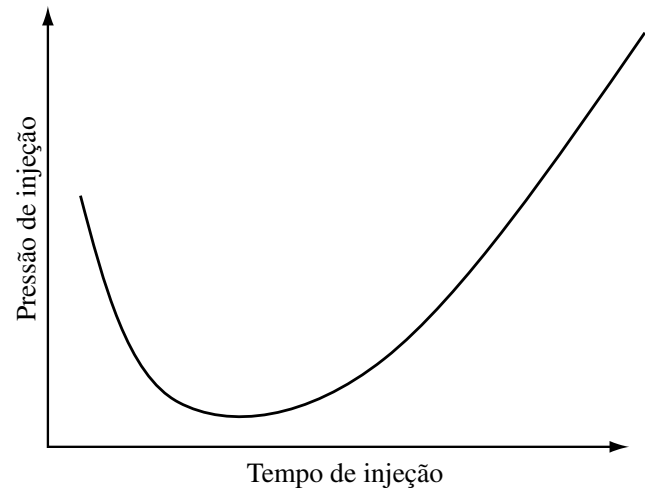

Figura 7. Gráfico em "U” para o balanço entre a pressão e o tempo de injeção.

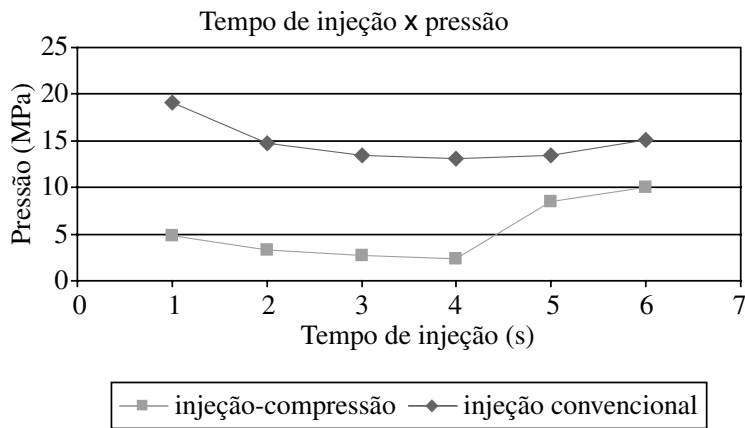

Figura 8. Pressão vs. tempo de injeção. 


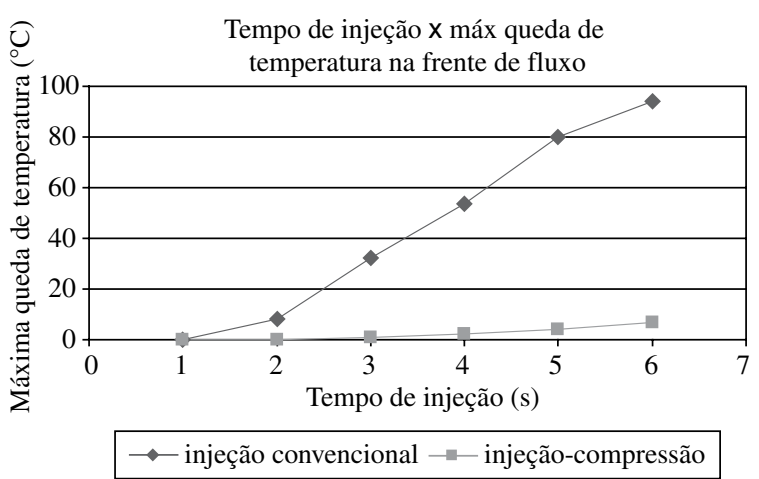

Figura 9. Queda de temperatura na frente de fluxo vs. tempo de injeção.

de falha de injeção. A alta viscosidade resultante gera altos valores de tensão de cisalhamento no final do preenchimento, gerando tensões residuais na peça moldada.

A frente de fluxo com velocidade constante minimiza o risco de haver degradação do material devido ao alto cisalhamento, que gera defeitos na peça como: marcas de queima, esfoliação e "gotas frias" ${ }^{[6]}$. O avanço da frente de fluxo com velocidade constante pode ser garantido na fase de compressão através de determinação de velocidade ótima de fechamento das placas. Para obter-se fluxo de velocidade constante foi necessária velocidade no fechamento das placas de $0,1 \mathrm{~cm} / \mathrm{s}$. Dessa forma, chegou-se à condição de processo otimizada, descrita na Tabela 5.
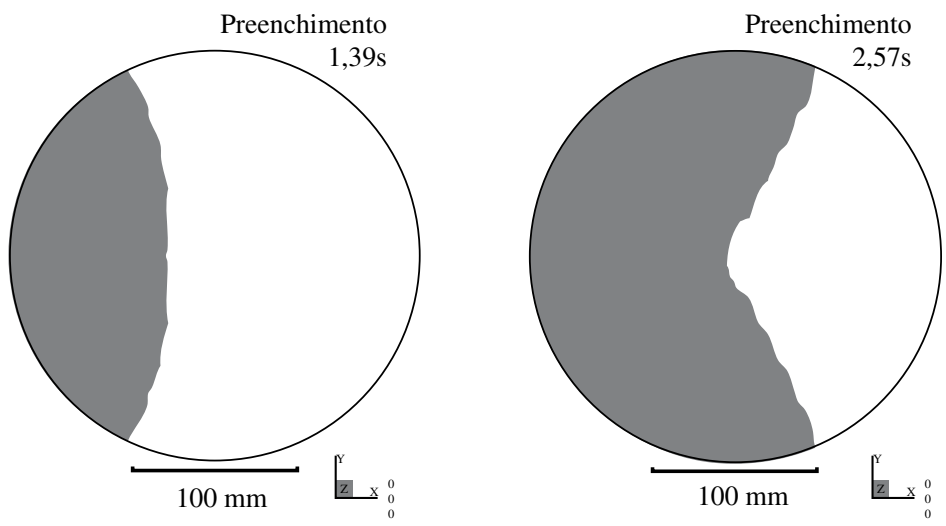

Figura 10. Padrão de preenchimento - injeção convencional.
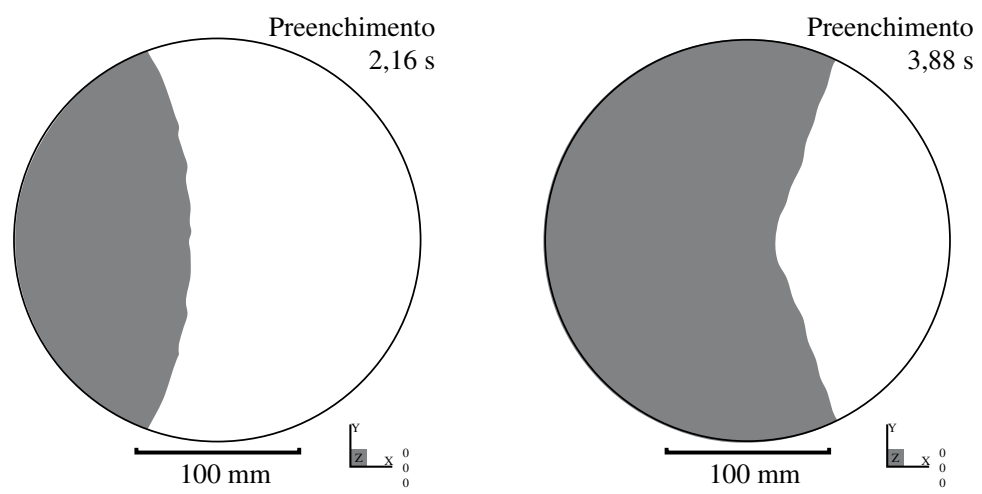

Figura 11. Padrão de preenchimento - injeção compressão.
Na Figura 10, verifica-se o padrão de preenchimento da cavidade para o processo de injeção convencional adotandose tempo de preenchimento da cavidade de 4 segundos.

Na Figura 11, verifica-se o padrão de preenchimento para o processo de injeção-compressão adotando-se tempo de preenchimento de 4 segundos e somada a etapa de compressão, $\sim 2$ s, i.e., com abertura/ vel. de fechamento iguais a $2 \mathrm{~mm} / 0,1 \mathrm{~cm} / \mathrm{s}$, respectivamente, totalizando cerca de $6 \mathrm{se}$ gundos.

É possível verificar a diferença nos dois processos, principalmente quanto ao tamanho da linha de emenda formada, ou seja, $69 \%$ menor no processo de injeção-compressão e ao provável aprisionamento de gás observado no processo convencional, resultantes do forte atraso no fluxo durante o preenchimento. A temperatura mínima de formação da linha

Tabela 5. Condições de processos finais otimizados.

\begin{tabular}{lcc}
\hline \multicolumn{1}{c}{ Parâmetros } & $\begin{array}{c}\text { Injeção } \\
\text { convencional }\end{array}$ & $\begin{array}{c}\text { Injeção- } \\
\text { compressão }\end{array}$ \\
\hline Temperatura do molde $\left({ }^{\circ} \mathrm{C}\right)$ & 85 & 85 \\
Temperatura do material $\left({ }^{\circ} \mathrm{C}\right)$ & 300 & 300 \\
Tempo de injeção $(\mathrm{s})$ & 4 & 4 \\
Comutação $(\%)$ & 99 & 99 \\
Abertura de placas $(\mathrm{mm})$ & não se aplica & 2 \\
Atraso no fechamento $(\mathrm{s})$ & não se aplica & 4,1 \\
Velocidade de compressão $(\mathrm{cm} / \mathrm{s})$ & não se aplica & 0,1 \\
\hline
\end{tabular}


Tabela 6. Resumo dos resultados obtidos experimentalmente para os dois processos de injeção.

\begin{tabular}{lcc}
\hline \multicolumn{1}{c}{ Parâmetros } & Injeção convencional & Injeção-compressão \\
\hline Comprimento da linha de emenda & 110 & 33,6 \\
Temperatura mínima de formação de linha de emenda $\left({ }^{\circ} \mathrm{C}\right)$ & 246,5 & 295,7 \\
Aprisionamento de gás & sim & não \\
Pressão de injeção necessária (MPa) & 13,1 & 2,4 \\
Pico de tensão de cisalhamento (MPa) & 0,524 & 0,178 \\
Pico de força de fechamento (ton) & 39,5 & 11,2 \\
\hline
\end{tabular}

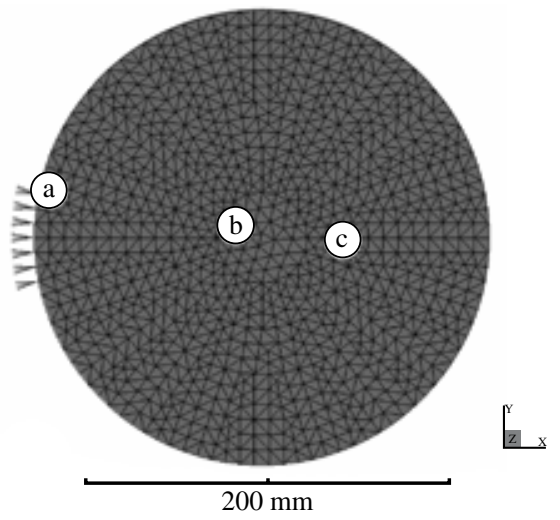

Figura 12. Nós adotados na medição da tensão de cisalhamento.

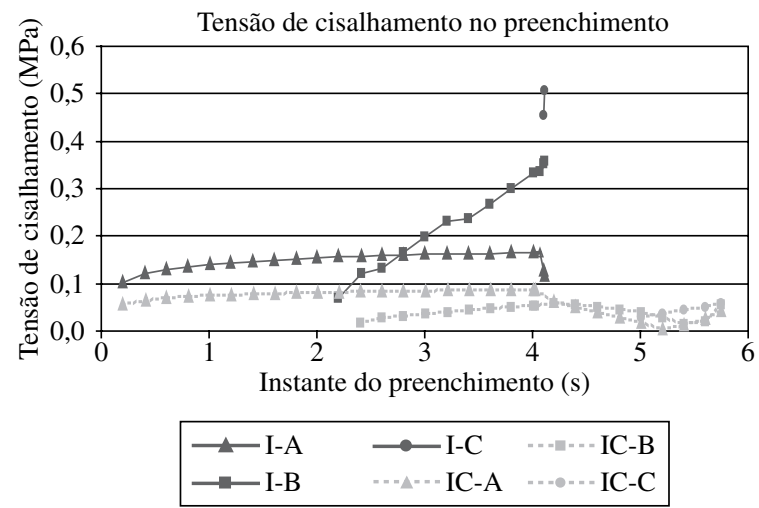

Figura 13. Tensão de cisalhamento.

de emenda para o processo de injeção convencional foi de $246,5^{\circ} \mathrm{C}$. Para o processo de injeção-compressão a menor temperatura na formação da linha de emenda foi de $295,7^{\circ} \mathrm{C}$. A formação de linha de emenda com maior temperatura garante melhor qualidade mecânica e estética para a peça.

Na Figura 12, são representados os nós adotados na medição da tensão de cisalhamento:

a) Ponto próximo à entrada de material; adotado devido à alta vazão;

b) Ponto na região de menor espessura da peça; adotado devido à forte hesitação nesse ponto durante o preenchimento da cavidade; e

c) Região posterior a 'b' no fluxo do material dentro da cavidade. O material nessa região apresenta alta viscosidade devido ao atraso no fluxo em 'b': gerando altos valores de tensão de cisalhamento.

$\mathrm{Na}$ Figura 13 é possível comparar os dois processos quanto ao cisalhamento do material nos pontos indicados.
Evolução da força de fechamento

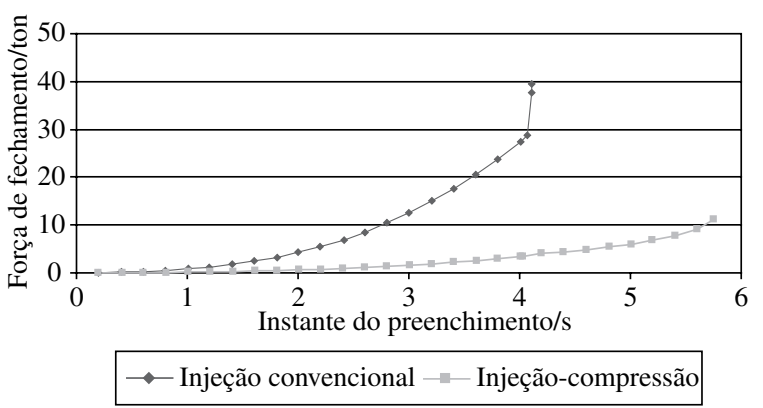

Figura 14. Força de fechamento.

As curvas denominadas "I-\#" referem-se ao processo de injeção convencional. As curvas denominadas "IC-\#” referem-se ao processo de injeção-compressão. Os dois processos não apresentaram grandes patamares de tensão de cisalhamento, uma vez que o limite indicado pelo fornecedor é de 0,5 $\mathrm{MPa}$. No processo de injeção convencional, para o ponto B o valor estabelecido pelo fornecedor é excedido, não sendo porém, mantido durante grande intervalo de tempo. Podemos concluir portanto não representar risco de degradação de material.

Na Figura 14, são comparados os níveis de força necessários para manter as placas fechadas durante o preenchimento da cavidade nos dois processos. O pico de força de fechamento para os dois processos são bastante discrepantes, ou seja, $72 \%$ menor para o processo de injeção-compressão, uma vez que o maior nível de pressão gerado dentro da cavidade durante o processo de injeção convencional é $82 \%$ menor para o processo e injeção-compressão. Conclui-se que na produção da peça estudada, o processo de injeção-compressão demandaria de uma máquina de menor porte.

A Tabela 6 representa o resumo comparativo dos resultados obtidos experimentalmente.

\section{Conclusões}

Por se tratar de uma peça para fins óticos, a linha de emenda é totalmente indesejada. $\mathrm{O}$ aprisionamento de ar ocorre na região central da peça - distante da linha de fechamento do molde, provavelmente impossibilitado de "escapar" durante o preenchimento da cavidade. Sob pressão, oferecerá forte resistência ao escoamento do material. Portanto as peças produzidas provavelmente apresentarão falha de injeção na região central ou marcas de queima devido à pressurização de 
ar na cavidade. Como alternativa ao problema pode-se cogitar a utilização de material poroso na região central do molde ou mesmo de saída de gases através de postiços. Essas duas alternativas, porém, resultariam em 'marcas superficiais' na peça; podendo comprometer sua funcionalidade.

Através do processo de injeção-compressão, a linha de emenda resultante é minimizada. Conclui-se, portanto, que para sua completa eliminação deve-se alterar a geometria (espessuras) da peça. Os resultados para os parâmetros estudados confirmam as vantagens do processo de injeção-compressão se comparado ao processo de injeção convencional no processamento e qualidade de peças óticas e de grande área projetada.

\section{Referências Bibliográficas}

1. Hofer, T. \& Fritz H. G. "Modeling and Simulation of the Injection-Compression Molding Process for Thin-Wall Parts", in: PPS International Annual Meeting, Montreal, Canada (2001).
2. Michaeli, W. \& Wielpuetz, M. Macromolecular Materials and Engineering, Aachen, Alemanha, 284, p.8-13 (2000).

3. Buchler, A., et al. Polymers in the automotive industry, 9, p.15 (2004).

4. Rios, A.; Davis B. \& Gramann P. “Computer Aided Engineering in Compression Molding", in: CFA Technical Conference, Tampa Bay (2001).

5. Manrich, S. "Processamento de termoplásticos", Artliber, São Paulo (2005).

6. Speight, R. G. et al. Revista Plástico Industrial, Aranda, São Paulo, 14, p.26-41 (1999).

7. Yang, S. Y. \& Chen, Y. C. Advances in Polymer Technology, Taipei, China, 17, p.353-360 (1998).

Enviado: 07/02/06

Reenviado: $14 / 08 / 06$

Aceito: $10 / 10 / 06$ 